\title{
Enhancing Classroom Learning Experience by Providing Structures to Microblogging-based Activities
}

\author{
Tian Luo \\ Ohio University, \\ Athens, $\mathrm{OH}$, USA
}

tl303308@ohio.edu

\author{
Fei Gao \\ Bowling Green State University, \\ Perrysburg, Ohio, USA
}

gaof@bgsu.edu

\section{Executive Summary}

Microblogging tools such as Twitter have been frequently adopted in educational settings to facilitate learning in recent years. Although the original purpose of microblogging tools is to connect with others in a wide network and instantly share what is happening to them with the rest of the world, educators have vigorously attempted to repurpose the utilization of the tool and integrate it into various educational settings to promote student learning.

The purpose of this study is to examine student learning experience under a set of structured microblogging-based activities and to identify the affordances and constraints of the technology. Students participated in the structured microblogging-supported collaborative and reflective activities during the class and reported their learning experience afterward. The analysis of in-class discussion transcripts, microblogging posts, pre- and post- survey results, and the after-class blog posts suggested that the structure provided by the instructor in these microblogging activities, allowed students to focus on the learning content and participate in an effective manner. The students' in-class participation and engagement were elevated by the microblogging-based activities, and they had an increased positive attitude towards the educational use of microblogging after the class activities.

This research suggests that providing structure to microblogging activities is critical to maximize the affordances and minimize the constraints of microblogging tools in a classroom setting. Specific structuring strategies employed in this study, such as presetting a code of conduct for tweeting, providing scaffolding to each tweeting activity, and setting a limited time frame, are worth considering for a successful microblogging application.

Keywords: microblogging, structured activity, collaborative learning, interaction, synchronous communication, technology integration

Material published as part of this publication, either on-line or in print, is copyrighted by the Informing Science Institute. Permission to make digital or paper copy of part or all of these works for personal or classroom use is granted without fee provided that the copies are not made or distributed for profit or commercial advantage AND that copies 1) bear this notice in full and 2) give the full citation on the first page. It is permissible to abstract these works so long as credit is given. To copy in all other cases or to republish or to post on a server or to redistribute to lists requires specific permission and payment of a fee. Contact Publisher@InformingScience.org to request redistribution permission.

\section{Introduction}

Microblogging is an online blogging tool that allows a small amount of textbased content to be published on the user's profile page (Java, Song, Finin, \& Tseng, 2007). By microblogging, users are able to connect with people in a wide network and share what is happening with the rest of the world (Holt, 
2011; Thames, 2009). Some microblogging tools also allow for multimedia content, where users can exchange small elements of multimedia content such as text messages, individual images, and video links (Holotescu \& Grosseck, 2009). The best-known microblogging tool is Twitter, which was launched in 2006. There are a great number of other microblogging platforms, such as Tumblr, Jaiku, Qaiku, and Yammer. By the end of 2011, Twitter by itself had 200 million users (Shiels, 2011).

The unique affordances of microblogging in education have gained researchers' attention in recent years. According to research, microblogging can serve as a mediating platform for studentstudent and student-teacher interaction. It can engage students in a classroom environment and enhance peer-to-peer interactivity, in-class participation, collaborative learning, and critical and reflective learning (Ebner, Lienhardt, Rohs, \& Meyer, 2010; Lowe \& Laffey, 2011; McWilliams, Hickey, Hines, Conner, \& Bishop, 2010; Rinaldo, Tapp, \& Laverie, 2011). However, how to design classroom activities to optimize the positive effects of microblogging remains a challenge for educators. The purpose of this study is to examine student learning under a set of structured microblogging-based activities and to identify the affordances and constraints of the technology.

\section{Educational Use of Microblogging Tools}

Microblogging has been adopted in different educational settings for a variety of educational purposes. Research suggested that it benefits in-class formal learning by enriching instructors' lecturing and enhancing students' engagement. Ebner and Maurer (2009) state that microblogging provides a means for students to have just-in-time interaction with their classmates on course content. Research has revealed that with microblogging, students are able to participate in classroom discussion at a level that they would not normally do. Junco, Heiberger, and Loken (2011) report that the use of Twitter encouraged online participation from some students who otherwise might not be active participants in class. Similarly, Rankin (2009) noted that the integration of Twitter, as a communication tool, allowed more students to participate in classroom discussion than before.

Microblogging tools were also found to benefit informal learning beyond the classroom. Twitter assignments have been demonstrated to promote active learning by helping students relate the course material to their own experiences both in and outside the classroom (Junco, Heiberger, \& Loken, 2011). In Dunlap and Lowenthal's (2009) research, Twitter was perceived as a tool which students could use to support informal learning activities, discover relevant resources, and seek help with their coursework. Ebner and Maurer (2009) stated that microblogging allowed learners to stay connected and share information in the eLearn community.

The formation of a learning community is another commonly-investigated theme. Students in Ebner and Maurer's study (2009) found that a sense of community and network building were enhanced by microblogging. Other researchers affirmed that the adoption of Twitter enabled sustained discussion and the building of a strong learning community among students (Borau, Ullrich, Feng, \& Shen, 2009; Junco et al., 2011). More importantly, learning communities built on microblogging tools can remain active after the course completion and continue to serve as a platform for learners to interact and collaborate (Dunlap \& Lowenthal, 2009; Holotescu \& Grosseck, 2009).

Researchers have also investigated collaborative learning activities enabled by microblogging tools. For example, in McWilliams and colleagues' (2010) study, students participated in a microblogging-based literacy activity to practice their writing and reading in the target language, where they were asked to act as different characters in a play and tweeted towards one another Likewise, Holotescu and Grosseck (2009) designed six collaborative learning activities with a microblogging platform called Cirip.ro to boost students' responsiveness to class discussion to 
and provide opportunities for collaborative learning. Perifanou (2009) states that the in-class microblogging activities promoted collaboration, motivation, and participation of her language class.

In many studies, however, microblogging has been incorporated without much structure, guidance, or support from the instructors. Some researchers have called for careful planning of microblogging activities to avoid distraction or information overload so as to maximize the benefits (Holotescu \& Grosseck, 2009; McWilliams et al., 2010), but very few studies have been done to examine how to structure and support microblogging activities in classrooms. In our study, we structured a series of collaborative and reflective microblogging activities and investigated to what extent and in which aspects microblogging tools facilitate classroom learning. We also wanted to see if student perception of microblogging changed before and after the class activities. The research questions of this study are:

1) How did students participate in the structured class activities?

2) How did students perceive their experience? Was there a perception change in students' viewpoints on the microblogging integration before and after the implementation of the study?

3) What did students learn through the activities?

4) What were the perceived benefits and challenges of integrating microblogging as reported by the students?

\section{What's Twiducate?}

The microblogging tool we used in this study is called Twiducate, which is designed for educators. Compared to Twitter, it grants teachers more control over the online learning environment and provides a more secure space for interaction and collaboration. A teacher can create a private

\section{CW01dUCOCO Home Profile Avatar Teachers (1) Students (13) Links (10) Dates (2) Public Print Store Sign Out 502}

** We've made some changes. As such, please update the "month" field in your important dates. ** (Close)

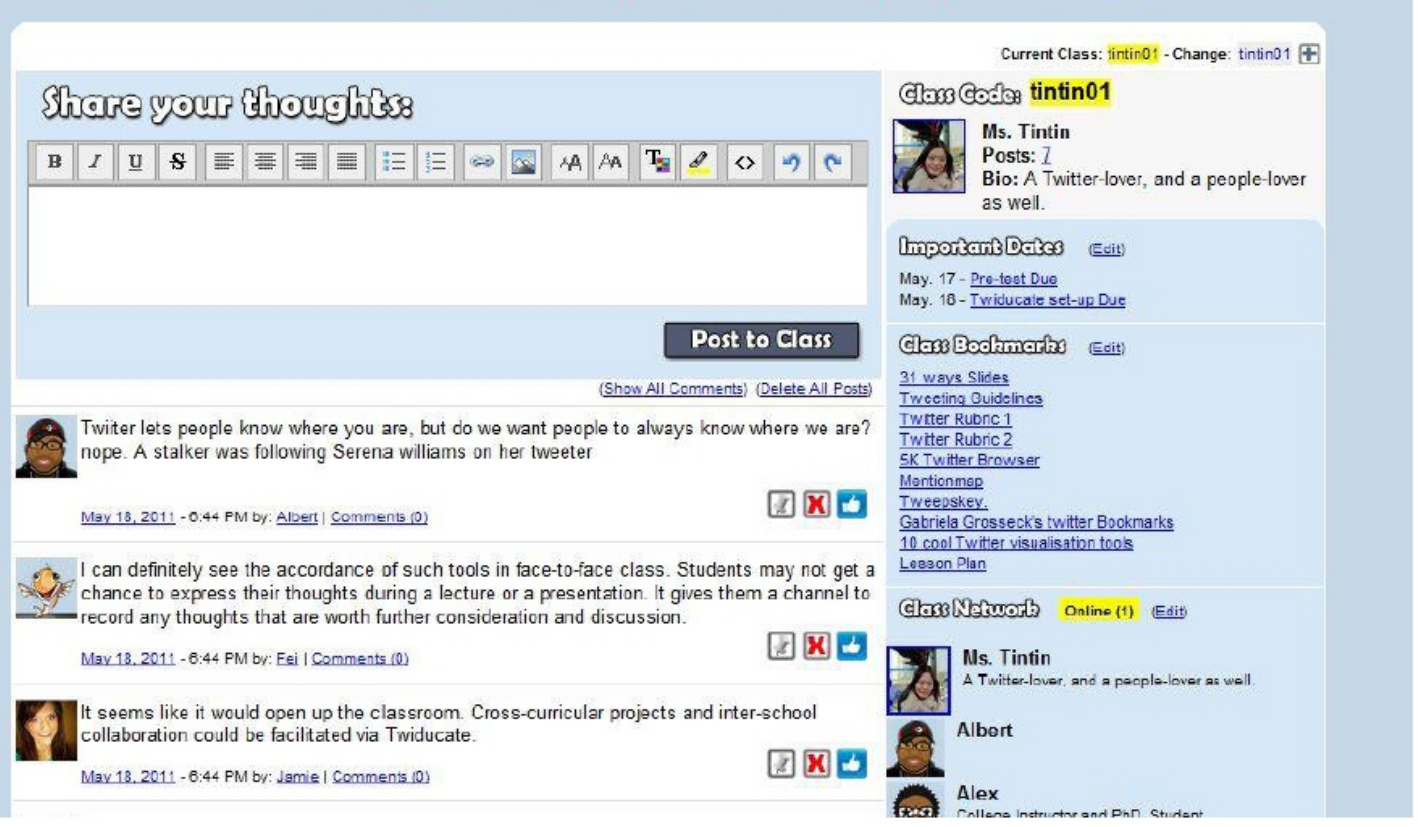

Figure 1. Screenshot of the Twiducate Interface 
learning network by adding all students to a private classroom space. Teachers have the freedom to create or delete posts, add class bookmarks, set important dates, and so on. In addition to posting tweets, Twiducate allows users to comment on existing tweets, which adds another layer of interaction among users. Finally, the "Like" function is incorporated for users to rate the tweets (Figure 1).

\section{Method}

\section{Participants}

Participants were ten graduate students taking a face-to-face class on the topic of using Web 2.0 tools in the classroom. Six of them were female and four were male. Four were between the ages of 25 to 30, four between 31 to 40, and two over 50. Of all the participants, six had a Twitter account, and eight had been using Twitter for more than one year. Among those who used Twitter, six had less than five tweets, and two had 6 to 20 tweets. Only one had heard of Twiducate prior to the class. Therefore, the students in this group were not active microblogging users.

\section{Procedures}

The goal of the lesson was to have students critically analyze the pros and cons of using microblogging tools in the classroom and construct their own understanding of incorporating Web 2.0 tools. Twiducate was incorporated into this lesson to encourage students' participation, reflective thinking, and collaborative learning. At the same time, it was used to demonstrate how a Web 2.0 tool can be integrated into classroom learning.

Pre-class preparation. Before the lesson started, the students were asked to familiarize themselves with the Twiducate environment. The instructor created a brief tutorial introducing the basic functions. Using the class code and password provided by the instructor, students logged into Twiducate, scanned through the interface, filled out the bio, and added a picture to their profile page.

Students were also asked to complete a pre-test survey prior to the in-class session. The pre-test provided the researchers an opportunity to understand students' familiarity with the tools, their level of interests, and their perception of the adoption of Twitter in education.

Learning activities. At the beginning of the lesson, the instructor walked through all the functions in Twiducate with the students and shared a set of tweeting guidelines in a dos and don'ts format on Twiducate. Some key guidelines were (a) follow the instructors' instructions carefully; (b) only tweet the topic in relation to the topic being discussed at the moment; and (c) do not tweet when the instructor does not ask you to. Such guidelines inform students how to participate in subsequent collaborative tweeting activities.

The instructor then implemented five Twiducate-supported activities. These activities attempted to facilitate student learning by providing sufficient support to help students tweet properly and effectively. In most of the activities, the instructor provided specific instruction and scaffolding questions for students to tweet, and reviewed and commented on the activities. In this way, problems such as information overload and distraction can be minimized.

Negotiating ways of participation. The first tweeting activity was a collaborative editing activity for students to negotiate rules and form a consensus on how to participate in subsequent activities. Students were asked to review the tweeting guideline document shared on Twiducate and edit it collaboratively using the similar dos and don'ts format. 
Brainstorming. This was followed by a face-to-face discussion. Topics, such as how to incorporate Twiducate into teaching and learning and strategies to design microblogging-based activities, were discussed in detail. After the discussion, the instructor posted five suggested topics on Twiducate for students to tweet, such as (a) what you have learned from the previous face-to-face discussion and (b) what you found particularly interesting about Twiducate. The students were given five minutes to write their tweets. Later, the instructor brought all the tweets into Wordle.net and made a word cloud to show the most-frequently-mentioned words.

Lecturing. After this, the instructor provided a lecture on different ways of using Twitter in the classroom, played an eight-minute video showing how Twitter was incorporated in an undergraduate class, and shared some rubrics for assessing tweets. During this lecturing session, students were allowed to freely post questions, thoughts, or ideas on Twiducate whenever they felt the need. They were also free to make any verbal comments during the lecturing session.

Discussing. When the lecture was over, students had another 5-minute discussion on Twiducate, where they could review what they had learned during the entire class. Questions, such as what are the most creative ways of using microblogging in educational settings, possible drawbacks and risks of using Twitter in the classroom, and strategies to design microblogging activities, were suggested for students to reflect upon. Students also reviewed and commented on their peers' tweets.

Debriefing. A quick debriefing session was designed in the end to sum up the class. Students used the "Like" function to select the three most reflective tweets posted during the preceding tweeting activities. The instructor then skimmed through these tweets selected by the students and summarized their major themes.

After-class evaluation. After completion of the lesson, students filled out a posttest survey to evaluate their experience of using Twiducate. The posttest survey consisted of three parts: students' self-evaluation of their in-class Twiducate experience, their perception of using microblogging tools in education, and open-ended questions asking them to justify their ratings and provide additional information about their experience; students also posted on the class blog about Twiducate.

\section{Data Analysis}

The research data in this study included the transcripts of students' face-to-face discussion, the text-based tweets on Twiducate, the pretest and posttest survey responses, and the after-class blog posts. All four data sources were triangulated, serving to answer the research questions.

The average number of student tweets and the average number of words in a tweet were counted to show student participation in the tweeting activities. Student perception change was measured by calculating the mean and standard deviation of student ratings on their perception of the Twiducate experience in the pre-activity and post-activity survey. The transcripts of students' face-to-face discussion, the text-based tweets on Twiducate, students' responses to the survey questions, and the after-class blog posts were examined to better understand student learning. Finally, the open-ended questions in the post-test survey and the after-class blog posts were analyzed to identify the perceived benefits and challenges of using microblogs in education. 


\section{Results}

\section{Student Participation}

\section{Quantity}

During the entire session, a total of 52 tweets and seven comments were posted by students and seven tweets by the instructor. All ten students participated in each microblogging activity. On average, each student had approximately five tweets (mean=5.2, $\mathrm{SD}=2.53$ ). Unlike Twitter, posts on Twiducate do not have a 140-character limit, so the longest post had 80 words / 492 characters. The average length of the post was approximately 29 words / 180 characters. Seven comments on specific tweets also demonstrated the interaction among students, which was substantial given that students had limited time to tweet throughout the class.

\section{Quality}

The quality of student participation was high. Students' responses on Twiducate were more focused and reflective than their verbal responses, probably because a written form of conversation allows more time for in-depth thinking. Except for one tweet that was mistakenly posted twice, all 59 tweets were meaningful and relevant to the learning content.

To further illustrate this, here is an excerpt of tweets:

Instructor: Since we have learned some creative ways to integrate Twiducate into educational settings, what do you think of using microblogging in classroom now? Will you customize these ways that we've learned and incorporate them into your own teaching and how would you do that?

Student A: Twiducate is a cool tool for classroom collaboration. I think this can open dialogue between the students and the teacher.

Student B: Ideas [of using microblogs in classrooms]: Literature: Have the class collaborate on a story...one team/person could start, then the next could add on another idea, etc. Social Studies: tweet as someone else (historical/literary character) Science: Brainstorming, hypothesizing on the result of a class experiment. Music Class: Listen to this music and tweet where you imagine you are, what's going on, etc. Art: Locate an image on the web that is an example of a concept we're covering and post in your tweet.

Student C: I would be interested in giving this a try in my nursing classroom. I can see assigning one lead student to watch over 10 other student tweets. There would then be a group discussion and then the students who are my watchers can post to class the group answers. There would be multiple groups.

Student D: I would use Twitter to teach a language, like asking students to make up sentences through Twitter. In this way, they can also see other's sentences and learn from each other.

Student E: Twitter is great. It can be used for chatting, discussion, group work and much more. However, most of these activities you can do them with other tools a well. Unless there is evidence that Twitter does discussion, blogging and collaboration better than blackboard, wikis, WordPress blogs and others there is no reason anyone would want to move to Twitter unless for novelty effect.

The above excerpts revealed students' thinking of how to incorporate Twiducate into their own teaching environments. Students were able to relate what they learned about Twiducate to their own teaching practice and suggest specific ways of using them in their own classroom. Evidence 
of critical thinking also manifested, as student E pointed out the limitations of Twitter. Participation on this level of breadth and depth may not be possible in a face-to-face environment.

\section{Student Perceptions}

\section{Perceptions of class experience}

Table 1 displays the means and standard deviations of students' ratings of their experience of Twiducate-based activities. Overall, participants perceived a high value of incorporating Twiducate in this class. They found themselves highly engaged in these activities (Mean $=4.90 ; \mathrm{SD}=$ 0.88 ) and believed that Twiducate was a particularly effective tool for sharing educational resources, collaborative learning, and improving knowledge, though it was less effective for critical thinking.

Table 1 Student ratings of their Twiducate experience on a scale of 1 to 6

\begin{tabular}{lcc}
\hline \multicolumn{1}{c}{ Statements } & Mean & SD \\
\hline My overall Twiduacate experience is bad. & 1.70 & 1.06 \\
I am engaged in collaborative learning through Twiducate. & 4.90 & 0.88 \\
I am highly involved in the class partly because of Twiducate. & 4.30 & 1.06 \\
I am exposed to more educational resources. & 5.30 & 0.68 \\
My critical thinking is enhanced because of Twiducate. & 3.90 & 1.29 \\
This Twiducate experience is boring. & 1.80 & 0.79 \\
$\begin{array}{l}\text { I value Twiducate or Twitter as a useful tool to be integrated into } \\
\text { classroom. }\end{array}$ & 4.80 & 0.79
\end{tabular}

$1=$ strongly disagree; 2 = disagree; $3=$ slightly disagree; $4=$ slightly agree; $5=$ agree; $6=$ strongly agree

\section{Perception change}

We compared student ratings in the pre-activity and post-activity survey on the same set of questions to determine whether there is a perception change regarding the educational use of microblogging tools. Table 2 displays the means and standard deviations of students' ratings before and after the lesson.

We found that, overall, students' perception of microblogging integration became more positive in the posttest survey. Student ratings of four of the six items showed a relatively large improvement after the Twiducate implementation. As the survey items indicated, students perceived the use of microblogging tools to be less annoying, more fun, more likely to enhance collaborative learning, and they were more likely to continue the use of microblogging in the future. In contrast, there was a slight decrease for the first two items. Given the small sample size, we believe this slight decrease (less than .30) does not suggest a dramatic change in their ratings on the two items. 
Table 2 Student ratings on perceptions of using microblogging tools on a scale of 1 to 6

\begin{tabular}{|l|l|l|}
\hline \multicolumn{1}{|c|}{ Survey Items } & $\begin{array}{c}\text { Pretest Mean } \\
\text { (SD) }\end{array}$ & $\begin{array}{c}\text { Posttest Mean } \\
\text { (SD) }\end{array}$ \\
\hline I believe microblogging tools can contribute to learning. & $5.20(0.79)$ & $5.10(0.56)$ \\
\hline $\begin{array}{l}\text { I doubt the true value of using microblogging tools for } \\
\text { education. }\end{array}$ & $2.10(0.99)$ & $2.40(0.84)$ \\
\hline $\begin{array}{l}\text { I found Twiducate or Twitter annoying in classroom } \\
\text { setting. }\end{array}$ & $3.60(1.65)$ & $2.10(0.88)$ \\
\hline $\begin{array}{l}\text { Using microblogging tools like Twiducate or Twitter in } \\
\text { classroom is fun. }\end{array}$ & $4.20(1.14)$ & $5.40(0.84)$ \\
\hline $\begin{array}{l}\text { I see using Twiducate or Twitter can enhance collabora- } \\
\text { tive learning in classroom. }\end{array}$ & $4.00(1.05)$ & $5.10(0.74)$ \\
\hline $\begin{array}{l}\text { I will continue the use of microblogging tools in the fu- } \\
\text { ture. }\end{array}$ & $3.70(1.42)$ & $4.70(1.50)$ \\
\hline
\end{tabular}

$1=$ strongly disagree; 2 = disagree; $3=$ slightly disagree; $4=$ slightly agree; 5 = agree; $6=$ strongly agree

\section{Student Learning}

The analysis of students' in-class text-based tweets, their discussion transcripts, and the afterclass blog posts revealed what they learned in this class.

First of all, students learned ways to incorporate microblogging tools into classroom settings. Three of them mentioned in their tweets the possibility of using them as documentation tools in and out of class for recording students' learning progress or achievements. One of them commented that "This can definitely be used in a class with multiple people to provide instant feedback to questions." Another one noted that they can be used anonymously in classroom settings to encourage students who are shy and introverted to participate in the discussion. Some other students perceived the value of using Twiducate as a comment tool - "I would like to use it as a comment platform. While students are doing their presentation, others can tweet whatever they find interesting about the presentation, or what they like about the presentation." Students also named several creative ways of using Twiducate in classrooms, such as using it for brainstorming or role-playing activities in history and literacy classes.

Second, students became aware of the advantages of using microblogging tools for educational purposes. In their tweets, we found that students discussed how these tools could enhance student engagement and classroom interactivity - "It seems like it would open up the classroom. Crosscurricular projects and inter-school collaboration could be facilitated via Twiducate." Students also recognized Twiducate as a tool to enhance collaboration. For instance, three of them noted that students can act as different characters in a story or play and learn the content material collaboratively. Another affordance discussed was the ability to facilitate after-class learning. Students brought up that Twitter can help connect students and parents - "I think Twitter is really useful as a quick and easy way to shoot updates out to parents."

Lastly, students discussed challenges of using Twiducate in-classroom. One of the biggest challenges is to overcome the potential distraction and information overload that may be triggered by the use of microblogging tools. Seven of ten students noted the importance of having scaffolding 
and guidance for microblogging activities. Students also raised the issue that it was very difficult for teachers to tease out and categorize the tweets based on discussion topics in classroom environments.

In the survey questions, students evaluated their learning experience in two items. The first item, "I do not learn much in this Twiducate class", had a mean of 1.70 and a standard deviation of 0.68. The mean and standard deviation for the second item, "I perceive a knowledge growth through this Twiducate experience", were 4.70 and 0.95 respectively. This indicated a positive learning experience reported by the students. The small SD value also showed low variability in their learning experience.

\section{Benefits and Challenges of Microblogging in Education}

Students responded to seven open-ended questions regarding the affordances and constraints of microblogging in education. The first section of the open-ended questions asked students in general what are the perceived advantages, constraints, and challenges of using microblogging tools in education. The second section was about whether and how microblogging afforded social presence, collaborative learning, critical thinking, and student engagement. The last section asked about the value of providing specific guidelines, rules, and manners in microblogging-supported activities. In this section we combined student responses to these questions and their reflections in the after-class blog posts to address the perceived affordances and challenges of using microblogging tools in education in general.

\section{Perceived affordances}

Students perceived ample merits of microblogging in improving classroom engagement and interactivity. The integration of microblogging was also perceived as beneficial to enhancing collaborative learning and informal learning.

Student engagement. Students recognized microblogging as a powerful way to involve all students, especially those who are shy and less outspoken in a face-to-face class. In addition, students reported that its affordances reside in its "ubiquitousness", which allows students to ask questions whenever and wherever in need and allows teachers to provide timely feedback. They thought that the "sense of novelty" associated with a new technology also contributed to an increased engagement.

Interactivity. Students affirmed microblogging's value in enhancing students' interactivity. Six out of ten students acknowledged that they believed student-student and student-teacher interaction were elevated by microblogging. One possible reason, as a student pointed out, could be "it makes the communication less formal." As a result, students were more likely to speak out as compared to when they were in a traditional face-to-face classroom.

Collaborative learning. Microblogging was also noted as a suitable tool for collaborative learning. Participants stated that it could motivate students to think and participate actively in a brainstorming session. One of them noted that microblogging allows for collaboration, especially among large groups so more people's voices are heard. A few suggested that a well-planned microblogging activity could greatly facilitate the collaborative group learning process.

Informal learning. Students commented on the value of using microblogging for after-class informal learning. As one student put it, "It would be a useful way to solidify the learning experience especially for after-class learning." Sharing resources, thoughts and reflections were often mentioned as ways for sustained learning after class. 


\section{Perceived challenges}

Students recognized that challenges coexist with the benefits of these tools. How to address issues such as information overload and how to design microblogging-enhanced learning activities were the two most frequently discussed issues.

Information overload. Three students stated that it was difficult for instructors to keep track of and pay special attention to all the tweets when a huge number of tweets were created. They noted that it would be a considerable problem when instructors used microblogging for live interaction in a large class with more than 50 students. Instructors would find it difficult to identify important tweets or draw students' attention to some specific tweets.

Having fun versus learning. Multiple students stated that being able to have fun is one important motivational factor for having students use microblogging tools. However, students agreed that too much focus on "having-fun" would bring distractions, which could possibly harm actual learning. One of them stated that putting too much control over students would make some students "feel resistant to use their 'fun' tool in class." Therefore, a balance of fun and learning elements should be designed into the activities.

Learning activity design. Five students noted the importance of designing structured activities. As one student stated, "My biggest concern is that how we can keep students focused on one task? [M] icroblogging could be distractive some time. In this case, I agree that establishing rules for the use of microblogging is very important, especially for young kids. And again, the way of its implementation into the classroom should be carefully designed, or it might cause some unexpected problems." Students also acknowledged the potential risks when appropriate structure or guidance is absent - "students would be tweeting random and meaningless stuff which has nothing to do with the class," and "the whole classroom environment would be out of control and mess-up." Additionally, students suggested that designing well-structured activities demands more efforts from the instructor - "it really depends how the instructor plans the activity; and we all know it's not easy."

\section{Discussion}

The analysis of students' tweets, discussion, and survey responses suggested that students' inclass participation and engagement were elevated by the microblogging-based activities. Some aspects of students' perceptions on the microblogging integration changed significantly after the class activities. Many students (seven out of ten) wrote in their tweets or their after-class blog entries that their collaborative learning experiences on Twiducate were unexpectedly satisfying. The success may be a result of providing structure around microblogging activities. One of the main challenges of using microblogging tools in classrooms is that the tweets are sometimes too short and too transient to create any meaningful reflection and too many irrelevant tweets could cause distraction from learning (Ebner et al., 2010). Another challenge is the difficulty in organizing tweets or teasing out tweets based on discussion topics in microblogs. Hence, when it comes to discussing multiple topics, the tweets could be disorganized and messy. Designing structured activities may help overcome certain challenges of using microblogging tools.

In our study, the instructor strived to employ structured activities to ameliorate the abovementioned issues that have often occurred when using microblogging tools. The instructor first set the rules and guidelines for tweeting in advance together with the students. As recognized by students, the rules and guidelines reinforced the learning purposes of the tweeting activity and helped eliminate potential distraction that could have been triggered by microblogging. Furthermore, the instructor stated the purpose of the tweeting activity and provided specific questions for students to tweet responses to in each activity. The well-structured activities provided students with instructional support and kept them on task. Therefore, when instructors reviewed the tweets 
in the end of the course, students' tweets were well organized based on the themes and topics preset by the instructor. Lastly, the five-minute limited time frame forced participants to concentrate on the topic raised and effectively restrained potential digression. As a result, well-structured activities may greatly lessen the effects of information overload and digression, allowing students to focus on the learning content and participate in an effective manner.

The structured activity design can also provide a balance between fun and learning in a microblogging-enhanced instructional environment. Researchers suggest that fun is an important element in technology-supported learning (Hoffman \& Nadelson, 2009; Perifanou, 2009). In particular, Perifanou (2009) states that learning on new social software application supports studentcentered learning and promotes motivation and participation. If the fun element is overemphasized, however, it can lead to digression and even distraction from the learning content. In our study, students had a lot of fun in this lesson, evidenced by the perception change in the survey responses, but at the same time, structures were provided to encourage focused discussions and avoid discussion being carried away by enjoyable but unrelated topics, thus creating a balance of fun and learning.

It is worth noting that the success in this case can be due to other factors. As reported in the pretest survey, the majority of the students were new to microblogs. The sense of novelty may have motivated them to actively participate in the activities. Additionally, all participants in this study are in the instructional technology program, so they might have been more open to trying and accepting new technologies.

Based on our study, we have a few recommendations for designing microblogging-based learning activities. First and foremost, teachers need to take an active role in designing and implementing the activities. As noted in many research studies and our own study, collaborative activities require a large amount of time and effort from instructors and often could be time-consuming and demanding. As educators, we need to take the initiative to think through the potential gain and cost of technology integration and analyze the possible pros and cons before we incorporate microblogging into our classroom. Only creative, precisely-planned, and carefully-conducted activities can lead to positive results (Holotescu \& Grosseck, 2009). In addition, teachers need to take into consideration both learning content and the characteristics of their students, choosing appropriate strategies based on gender, age, grade level and so on. Strategies such as breaking students into groups, having someone monitor the tweets and deal with technical difficulties, and giving students time to reflect on and process information would be good practices that teachers can adopt for their own classes (Dunlap \& Lowenthal, 2009; Rankin, 2009). Lastly, prior to the inclass tweeting activities, it is desirable to design a written code of conduct that students and teachers both agree on, so that all participants accept and follow the same tweeting rules.

\section{Conclusion}

This study examines students' learning experience in a set of structured microblogging-based class activities. Different from most previous research studies, this study attaches great importance to structured activity design in the field of microblogging-enhanced instruction. The instructor in this study provided students with considerable support when asking them to participate in the microblogging activities, which is critical but rarely seen in preceding research (Dunlap \& Lowenthal, 2009; Holotescu \& Grosseck, 2009).

Students benefited from the structured Twiducate-supported activities in the following ways. The quantity and quality of their participation in this face-to-face class were each improved due to active engagement with the microblogging tool (Twiducate). Many of them achieved a positive perception change after the Twiducate-supported collaborative learning activities. 
In this study, we raised the issue of how to maximize the affordances and minimize the constraints of microblogging tools by providing structure to microblogging activities. Specific structuring strategies, such as presetting a code of conduct for tweeting, providing scaffolding to each tweeting activity, and setting a limited time frame, are worth considering for a successful microblogging application. Since this is an exploratory study with a small sample size, the impact and effectiveness of the structuring strategies has not been fully tested. Research conducted with a larger group is needed to test its applicability and generalizability. Researchers should also investigate the learning gains of using microblogging tools by isolating the novelty effect and other potential extraneous factors. Finally, more rigorous methods to measure participation and engagement are needed in future research in addition to self-report surveys.

\section{References}

Borau, K., Ullrich, C., Feng, J., \& Shen, R. (2009). Microblogging for language learning: Using Twitter to train communicative and cultural competence. Paper presented at the Advances in Web Based Learning-ICWL 2009.

Dunlap, J. C., \& Lowenthal, P. R. (2009). Tweeting the night away: using Twitter to enhance social presence. Journal of Information Systems Education, 20(2), 129-155.

Ebner, M., \& Maurer, H. (2009). Can weblogs and microblogs change traditional scientific writing? Future Internet, 1(1), 47-58. doi: 10.3390/fi1010047

Ebner, M., Lienhardt, C., Rohs, M., \& Meyer, I. (2010). Microblogs in higher education - A chance to facilitate informal and process-oriented learning? Computers \& Education, 55(1), 92-100. doi: 10.1016/j.compedu.2009.12.006

Hoffman, B., \& Nadelson, L. (2009). Motivational engagement and video gaming: A mixed methods study. Educational Technology Research and Development, 58(3), 245-270. doi: 10.1007/s11423-009-9134-9

Holotescu, C., \& Grosseck, G. (2009). Using microblogging in education . Case Study: Cirip. ro. Network, 1(1), 2-5. American University in Cairo. Retrieved from http://www.scribd.com/doc/8551345/Using-microblogging-in-education-Case-Study-Ciripro

Holt, C. (2011). Emerging technologies Web 2.0. Health Information Management Journal, 40(1), 33-35.

Java, A., Song, X., Finin, T., \& Tseng, B. (2007). Why we twitter: Understanding microblogging usage and communities. Proceedings of the 9th WebKDD and 1st SNA-KDD 2007 workshop on Web mining and social network analysis, San Jose, California.

Junco, R., Heiberger, G., \& Loken, E. (2011). The effect of Twitter on college student engagement and grades. Journal of Computer Assisted Learning, 27(2), 119-132. doi: 10.1111/j.13652729.2010.00387.x

Lowe, B., \& Laffey, D. (2011). Is Twitter for the birds? Using Twitter to enhance student learning in a marketing course. Journal of Marketing Education, 33(2), 183-192. doi: 10.1177/0273475311410851

McWilliams, J., Hickey, D. T., Hines, M. B., Conner, J. M., \& Bishop, S. C. (2010). Voices from the field: Using collaborative writing tools for literary analysis: Twitter, fan fiction and the crucible in the secondary English classroom. Journal of Media Literacy Education, 3(3), 238-245.

Perifanou, M. A. (2009). Language micro-gaming: Fun and informal microblogging activities for language learning. Communications in Computer and Information Science, 49, 1-14. doi: 10.1007/978-3-64204757-2_1

Rankin, M. (2009). Some general comments on the "Twitter Experiment." Retrieved from http://www.utdallas.edu/ mar046000/usweb/Twitterconclusions.html

Rinaldo, S. B., Tapp, S., \& Laverie, D. A. (2011). Learning by Tweeting: Using Twitter as a pedagogical tool. Journal of Marketing Education, 33(2), 193-203. doi: 10.1177/0273475311410852 
Shiels, M. (2011). Twitter co-founder Jack Dorsey rejoins company. Retrieved from BBC News website: http://www.bbc.co.uk/news/business-12889048

Thames, G. (2009). Twitter as an educational tool. Journal of Child and Adolescent Psychiatric Nursing, 22(4), 235-235. doi: 10.1111/j.1744-6171.2009.00208.x

\section{Biographies}

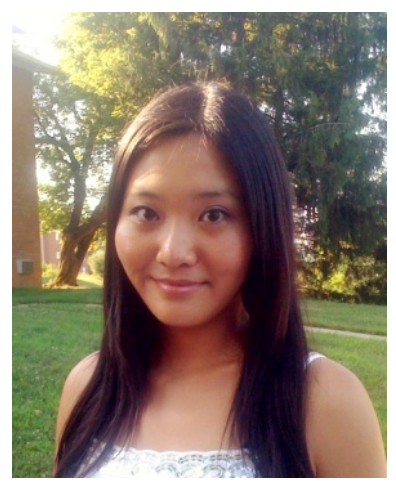

Tian Luo is a second-year doctoral student in the Department of Educational Studies at Ohio University. Her research interests centre on using social media and social technologies to facilitate student learning in formal and informal educational settings and designing a collaborative learning environment facilitated by various web-based technologies. She has presented at multiple conferences in the field of educational and instructional technology including World Conference on ELearning in Corporate, Government, Healthcare, and Higher Education and Society for Information Technology and Teacher Education International Conference.

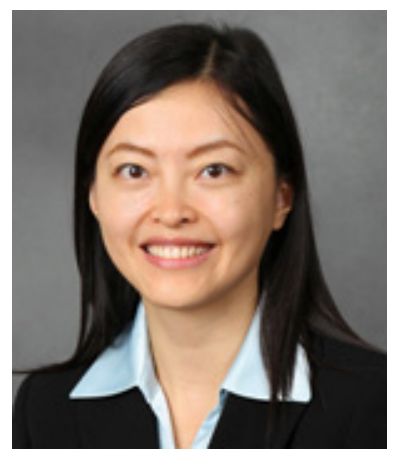

Fei Gao is an assistant professor in Learning Design at Bowling Green State University. Her research focuses on designing technologyenhanced environments that foster meaningful interaction and assessing the effectiveness of such environments. Fei was an Assistant Professor at Ohio University prior to joining BGSU; she also worked as an instructional designer at Montclair State University. Her research has been published at British Journal of Educational Technology, Journal of Interactive Learning Research, Journal of Educational Computing Research, Journal of Educational Multimedia and Hypermedia, and International Journal of Instructional Media. 